\title{
Know TB to No TB: IAP Presidential Action Plan 2014
}

\author{
ViJAY N YeWALE \\ National President, Indian Academy of Pediatrics, 2014 \\ vnyewale@gmail.com.
} "Wherever there are infected tuberculous adults, there
are infected children. Nobody is immune"...

These were the famous words of Edith Lincoln - a pioneer in the field of pediatric tuberculosis (TB) - who originally observed the natural history of tubercular infection and disease in children, about half a century ago [1]. Today, millions of children are exposed to adult tuberculosis which reports an alarming trend of multidrug-resistant (MDR: resistant to at least rifampicin and isoniazid) and extensively drug-resistant (XDR: additionally resistant to a fluoroquinolone and kanamycin/amikacin/capreomycin) strains. The threat of drug resistance in children has become a reality with the WHO global report 2013 [2] stating that a child with TB is as likely as an adult with TB to have MDR-TB. It is estimated that anywhere between 10000 and 20000 children in India might be acquiring MDR-TB every year [3].

There are many challenges in diagnosis of pediatric tuberculosis as compared to adults: lower bacterial load, higher rates of extrapulmonary tuberculosis and lack of tussive force to obtain a sputum sample to demonstrate acid-fast bacilli for confirmation of active TB. The diagnosis of MDR-TB, which relies on a positive culture and drug sensitivity report, becomes even more challenging. Often, clinical criteria are relied upon for diagnosis along with radiological support and Mantoux testing. Many children with bacteriologically/ histopathologically proven tuberculosis may have normal chest radiograph [4]. Insensitive diagnostic aids have led to delayed diagnosis/underdiagnosis/ overdiagnosis. Although children usually develop transmitted drug-resistant TB, some may acquire drug resistance due to inadequate treatment regimen, irregular supply of drugs or poor compliance. There are many missed opportunities - to prevent transmission of disease by household adult contacts to children - with effective chemoprophylaxis.

The pediatric TB and its drug resistance situation in India can be viewed as a ticking timebomb. Taking serious note of this emerging health crisis, the Academy has decided to lay a significant focus on intense training of its members in case detection, timely diagnosis, ensuring adherence, monitoring adverse effects and appropriate timely referral to experts for dealing multidrug- resistant disease. Our national strategy needs to prioritize pediatric TB with a uniform access of quality of diagnosis and care. A National consultation by experts was done in JanuaryFebruary 2012 to review the existing evidence and update the Revised National Tuberculosis Control Program (RNTCP) guidelines for diagnosis and management of pediatric TB. It also addressed the various issues in programmatic implementation, like new weight bands, to prevent under-dosing or over-dosing. The updated guidelines were published in 2013 [5]. The Academy now plans to take another step forward by partnering with the Child TB Division (CTD) of the Ministry of Health and Family Welfare and RNTCP, to develop a two day course for training the pediatricians on management of pediatric tuberculosis. A case-based interactive module will be prepared to train the pediatricians all over the country.

Individual and community measures to hit the brakes on TB are urgently needed to avoid the nightmare of losing our children to TB, or struggling with increasing drug resistance using expensive, long regimens with more toxic drugs - the safety and efficacy of which remain unclear in children.

\section{REFERENCES}

1. World Health Organization. Roadmap for Childhood Tuberculosis: Towards Zero Deaths. Geneva: WHO, 2013.

2. World Health Organization. Global Tuberculosis Report 2013. Geneva: WHO, 2013.

3. Swaminathan S. Drug resistance in childhood tuberculosis - invicible and unnoticed. Pediatr Infect Dis. 2012;4:41-2.

4. Swaminathan S, Datta M, Radhamani MP, Mathew S, Reetha AM, Rajajee S, et al. A profile of bacteriologically confirmed pulmonary tuberculosis in children. Indian Pediatr. 2008;45:743-7.

5. Kumar A, Gupta D, Nagaraja SB, Singh V, Sethi GR, Prasad J; Indian Academy of Pediatrics. Updated national guidelines for pediatric tuberculosis in India, 2012. Indian Pediatr. 2013;50:301-6. 